\title{
Effect of thermomechanical processing on microstructure and mechanical properties of the carbon-containing CoCrFeNiMn high entropy alloy
}

\author{
N.D. Stepanov ${ }^{\text {a, * }}$, D.G. Shaysultanov ${ }^{\text {a }}$, R.S. Chernichenko ${ }^{a}$, N. Yu Yurchenko ${ }^{\text {a }}$, \\ S.V. Zherebtsov ${ }^{\text {a }}$, M.A. Tikhonovsky ${ }^{\text {b }}$, G.A. Salishchev ${ }^{\text {a }}$ \\ a Laboratory of Bulk Nanostructured Materials, Belgorod State University, Belgorod 308015, Russia \\ bational Science Center "Kharkov Institute of Physics and Technology" NAS of Ukraine, Kharkov 61108, Ukraine
}

\section{A R T I C L E I N F O}

\section{Article history:}

Received 15 July 2016

Received in revised form

28 August 2016

Accepted 20 September 2016

Available online 21 September 2016

\section{Keywords:}

High entropy alloys

Carbon

Microstructure

Thermomechanical processing

Mechanical properties

\begin{abstract}
A B S T R A C T
Microstructural evolution during cold sheet rolling to $80 \%$ thickness strain and annealing at $600-1100{ }^{\circ} \mathrm{C}$ for $30 \mathrm{~min}$ of the CoCrFeNiMn high entropy alloy doped with 1 at.\% of $\mathrm{C}$ and resulting mechanical properties of the alloy are reported. It is shown that in the initial homogenized $\left(24 \mathrm{~h}\right.$ at $\left.1000{ }^{\circ} \mathrm{C}\right)$ condition the alloy has single fcc phase structure. Cold rolling is accompanied by dislocation slip, deformation twinning and formation of shear bands. Annealing at $600{ }^{\circ} \mathrm{C}$ after $80 \%$ cold rolling results only in partial recrystallization of cold-deformed structure, while an increase of the annealing temperature produces fully recrystallized microstructure. Comparison with the data on undoped CoCrFeNiMn alloy demonstrates that the addition of carbon pronouncedly increases dislocation activity simultaneously retarding deformation twinning during rolling and decreases the fraction of twin boundaries in the annealed condition. The effect of carbon can be attributed to an increase of stacking fault energy of the carbon-containing alloy. Cold rolling results in a substantial strengthening of the alloy; its ultimate tensile strength approaches $1500 \mathrm{MPa}$, but at the expense of low ductility. Good combination of strength and ductility can be obtained after annealing. For example, after annealing at $800^{\circ} \mathrm{C}$, the alloy has yield strength of $720 \mathrm{MPa}$, ultimate tensile strength of $980 \mathrm{MPa}$, uniform elongation of $21 \%$ and elongation to fracture of $37 \%$. It is shown that the high strength of the annealed alloy can be attributed to (i) strong grain boundary strengthening; (ii) solid solution strengthening by carbon.
\end{abstract}

(C) 2016 Elsevier B.V. All rights reserved.

\section{Introduction}

The so-called high entropy alloys - alloys, composed of 5 or more principal elements in nearly equiatomic proportions [1,2] has recently attracted considerable attention from the materials scientists worldwide, mostly due to their encouraging mechanical properties [2-10]. One of the most promising and well-studied high entropy alloys is the equiatomic CoCrFeNiMn alloy [11]. It has a single phase face-centered cubic (fcc) structure stable at high temperatures [12-14], although there have been several reports that precipitation of secondary phases can occur after annealing at

\footnotetext{
* Corresponding author. Laboratory of Bulk Nanostructured Materials, Belgorod State University, Pobeda 85, Belgorod 308015, Russia.

E-mail addresses: stepanov@bsu.edu.ru, stepanov.nikita@icloud.com (N.D. Stepanov).
}

intermediate temperatures [15-17]. The alloy demonstrates remarkable work hardening capacity both at room and cryogenic temperatures, and thus high ductility $[18,19]$. Moreover, the $\mathrm{CoCr}$ FeNiMn has extremely high fracture toughness at room and cryogenic temperature, exceeding fracture toughness of the most other materials [20]. In general, mechanical behavior of the CoCrFeNiMn alloy resembles much that of high-Mn austenitic TWIP steels $[21,22]$. For example, both CoCrFeNiMn alloy and TWIP steels have the same disadvantage - relatively low yield strength $[18,19,23]$.

Several approaches can be used to improve the yield strength of the CoCrFeNiMn alloy. One of them is microstructure refinement through a thermomechanical treatment. High Hall-Petch coefficient was reported for this alloy [18,24]; therefore producing the fine recrystallized microstructure by hot/warm working [25] or cold working with subsequent annealing [26-31] can effectively increase the yield strength of the alloy while maintaining high ductility [18]. It should be noted that cold working without 
subsequent annealing results in very pronounced strengthening, but at the expense of dramatically reduced ductility $[15,22,32]$. Another approach is to modify the chemical composition of the alloy. There have been several reports on $\mathrm{Co}-\mathrm{Cr}-\mathrm{Fe}-\mathrm{Ni}-\mathrm{Mn}$ system alloys with non-equiatomic compositions and/or lower number of constitutive elements, and some of them demonstrated mechanical properties superior to that of the original CoCrFeNiMn alloy [21,33-39]. Additional alloying elements can also be introduced; for instance, it is well established that $\mathrm{Al}$ results in a significant strengthening of the CoCrFeNiMn-based alloys [40,41].

Carbon is the primal alloying elements of steels, including TWIP steels, which has a very pronounced effect on their mechanical properties [23]. But for the high entropy alloys the effect of alloying with carbon is still insufficiently studied [42-44]. First encouraging report was made on mechanical properties of the CoCrFeNiMn alloy containing 0.5 at.\% of carbon in fcc solid solution: the alloy has higher both yield strength and ultimate tensile strength, and more pronounced strain hardening capacity, which was ascribed to higher twinning activity than in the CoCrFeNiMn alloy [45]. However, the yield strength of the CoCrFeNiMn-0.5 at.\% $\mathrm{C}$ alloy at room temperature was not that high - only $225 \mathrm{MPa}$. On the other hand, exceptional properties were recently reported for the fcc structured $\mathrm{Fe}_{40.4} \mathrm{Ni}_{11.3} \mathrm{Mn}_{34.8} \mathrm{Al}_{7.5} \mathrm{Cr}_{6}$ alloy, which contained 1.1 at.\% of carbon [46]. The yield strength of the alloy was $355 \mathrm{MPa}$ in a coarsegrained condition $(\mathrm{d}=120 \mu \mathrm{m})$ or $557 \mathrm{MPa}$ in a fine-grained condition $(\mathrm{d}=4.7 \mu \mathrm{m})$, and the tensile ductility reached $\sim 50 \%$. Thus, the existing literature demonstrates that alloying with even a relatively small amount of carbon can be an effective way to enhance the mechanical properties of fcc structured HEAs. However, many aspects including the effect of carbon on deformation and strengthening mechanisms, microstructure-properties relationships and some others require additional studies.

Therefore, in current work we have studied the effect of thermomechanical processing of CoCrFeNiMn-C alloy, containing $\approx 1$ at.\% of carbon, on microstructure and mechanical properties of the alloys. According to results of [47], the alloy is anticipated to have single fcc phase structure without any second phase (carbide) precipitates. Typical thermomechanical processing scheme, including multipass flat rolling at ambient temperature with subsequent annealing, was used. Two following aims were pursued: (i) to obtain an alloy with a balanced combination of strength/ductility characteristics; and (ii) to get a better understanding of the effect of alloying with carbon on the mechanical properties of the $\mathrm{CoCrFe}-$ NiMn alloy.

\section{Experimental procedures}

The alloy with nominal composition of CoCrFeNiMn-1(at.\%)C $(\approx 0.2 \mathrm{wt} \% \mathrm{C})$, was produced by arc melting of the elements in a low-pressure, high-purity argon atmosphere inside a water-cooled copper cavity. The purities of the alloying elements were above 99.9 at.\%. To ensure chemical homogeneity, the ingots were flipped over and re-melted at least 5 times. The produced ingots had dimensions of about $6 \times 12 \times 40 \mathrm{~mm}^{3}$. Actual concentration of carbon in the alloy was measured with Leco analyzer and were found to be 0.97 at.\%. The alloy was studied after homogenization annealing carried out at $1000{ }^{\circ} \mathrm{C}$ for $24 \mathrm{~h}$. Prior to homogenization, the samples were sealed in vacuumed $\left(10^{-2}\right.$ torr $)$ quartz tubes filled with titanium chips to prevent oxidation. After annealing, the tubes were removed from the furnace and the samples were cooled inside the vacuumed tubes down to room temperature.

Rectangular samples measured $5 \times 10 \times 20 \mathrm{~mm}^{3}$ were cut by electric discharge machine to carry out thermomechanical processing. Unidirectional multipass rolling using a fixed rolling speed of $30 \mathrm{~mm} / \mathrm{s}$ at room temperature to a total thickness strain $80 \%$ was performed in air using a reduction per pass of approximately $0.2-0.07 \mathrm{~mm}$. The rolling strain was calculated from the thickness of produced specimens. After rolling to the final thickness, some specimens were annealed to produce recrystallized structure. Annealing was carried out at temperatures of $600{ }^{\circ} \mathrm{C}, 700{ }^{\circ} \mathrm{C}$, $800{ }^{\circ} \mathrm{C}, 900{ }^{\circ} \mathrm{C}, 1000^{\circ} \mathrm{C}$ and $1100{ }^{\circ} \mathrm{C}$ for $30 \mathrm{~min}$. For annealing, the specimens were placed in preheated oven and held for desired period of time. After annealing, the specimens were air cooled.

The microstructure of the alloy after rolling and annealing was studied using transmission (TEM), scanning (SEM) electron microscopy, EBSD analysis, and X-ray diffraction (XRD) analysis. In the case of the rolled samples, the microstructural investigations were carried out in the plane perpendicular to the transversal direction. The samples for SEM observations and EBSD analysis were prepared by careful mechanical polishing. SEM back-scattered electron (BSE) images were taken using FEI Quanta 3D microscope. EBSD was conducted in an FEI Nova NanoSEM 450 field-emission-gun scanning-electron microscope (FEG-SEM) equipped with a Hikari EBSD detector and a TSL OIM ${ }^{\mathrm{TM}}$ system version 6.0. The points with confidence index $(\mathrm{CI}) \leq 0.1$ were excluded from analysis. The samples for TEM analysis were prepared by conventional twin-jet electro-polishing of mechanically pre-thinned to $100 \mu \mathrm{m}$ foils, in a mixture of $95 \% \mathrm{C}_{2} \mathrm{H}_{5} \mathrm{OH}$ and $5 \% \mathrm{HClO}_{4}$ at the $27 \mathrm{~V}$ potential. TEM investigations were performed using a JEOL JEM-2100 microscope with accelerating voltage of $200 \mathrm{kV}$ equipped with energydispersive X-ray spectroscopy (EDS) detector. Dislocation density was evaluated using the results of XRD analysis. XRD analysis was performed using an ARL-X-tra diffractometer with $\mathrm{CuK} \alpha$ radiation at $45 \mathrm{kV}$ and $35 \mathrm{~mA}$. The value of the dislocation density, $\rho$, was calculated using the following equation [48]:

$\rho=\frac{3 \sqrt{2 \pi}<\varepsilon_{50}^{2}>}{D b}$

Where $\left\langle\varepsilon_{50}^{2}>\right.$ is microstrains, $D$ is the crystallite size, and $b$ is the Burgers vector $\left(b=2.58 \times 10^{-10} \mathrm{~m}^{-2}[22]\right)$. The microstrains, $\left\langle\varepsilon_{50}^{2}>\right.$, and the crystallite size, $\mathrm{D}$, values were estimated on the basis of the Williamson-Hall plot [49], using the equation:

$\frac{\beta_{s} \cos \Theta}{\lambda}=\frac{2<\varepsilon_{50}^{2}>\sin \Theta}{\lambda}+\frac{K}{D}$

where $\beta_{s}$ is the corrected full width at half maximum (FWHM) of the selected $K \alpha_{1}$ reflection of the studied material, $\Theta$ is the Bragg angle of the selected reflection, $\lambda$ is the $K \alpha_{1}$ wavelength, and $K$ is Scherrer constant. In the present study, FWHM values and positions of fcc (111) and (222) reflections were determined and used for further calculations. The instrumental broadening was determined from FWHM values of the annealed silicon powder.

Vickers microhardness tests of the specimens after rolling to different thickness reduction of $5-80 \%$ and after annealing at $600-1100{ }^{\circ} \mathrm{C}$ were conducted at room temperature using $300 \mathrm{~g}$ load. At least 10 measurements per each data point were made. Tensile properties of the alloy after $80 \%$ thickness strain and annealing at $700{ }^{\circ} \mathrm{C}, 800{ }^{\circ} \mathrm{C}, 900{ }^{\circ} \mathrm{C}$ and $1100{ }^{\circ} \mathrm{C}$ for $30 \mathrm{~min}$ (annealing temperatures were chosen by analysis of microhardness data) were determined. To this end, flat dog-bone specimens with gauge dimensions of $16 \mathrm{~mm}$ length $\times 3 \mathrm{~mm}$ width $\times 1 \mathrm{~mm}$ thickness, were cut by electric discharge machine and pulled at a constant crosshead speed of $1 \mathrm{~mm} / \mathrm{min}$ in an Instron 5882 test machine to fracture. The long axis of the specimens was aligned with rolling direction. Elongation to fracture was determined by measurements of spacing between marks designating the gauge length before and after the test. Three samples per each condition were tested. 


\section{Experimental results}

\subsection{The initial microstructure of the CoCrFeNiMn-1(at.\%)C alloy}

Fig. 1 characterizes the initial (homogenized) structure of the CoCrFeNiMn-1(at.\%)C alloy using data obtained by different experimental techniques: XRD (Fig. 1a) and EBSD (Fig. 1b). Additional SEM-BSE and TEM (results not shown) investigations were also performed. Detailed examination on different scales has revealed that the microstructure consisted of fcc solid solution without any other phases. The measured lattice parameter of the fcc phase of the CoCrFeNiMn-1(at.\%)C alloy equals to $0.3595 \mathrm{~nm}$, which is slightly higher than the fcc lattice parameter of the carbon-free CoCrFeNiMn alloy (0.3593 nm [47]). The higher lattice parameter of the carbon-containing alloy is most likely due to dissolved carbon. The alloy has a granular microstructure with equiaxed or elongated grains. The grain size in the homogenized condition is $250-300 \mu \mathrm{m}$. The presence of pores and manganese oxide particles, visible as black dots on EBSD image has to be noted.

\subsection{Effect of cold rolling on microstructure of the CoCrFeNiMn- 1(at.\%)C alloy}

Fig. 2 demonstrates EBSD IPF maps of the CoCrFeNiMn-1(at.\%)C alloy after cold rolling to different thickness strain. No noticeable changes in the homogenized microstructure of the alloy after rolling to $5 \%$ or $15 \%$ strain were detected by EBSD method. After $25 \%$ thickness strain, development of substructure and mechanical twinning becomes evident (Fig. 2a). Twinning and substructure develop heterogeneously - some grains contain numerous twins (an example is shown in a higher magnification insert in Fig. 2a), some contain several twins, while the majority of the initial grains contain mostly low-angle boundaries. The inhomogeneity of the deformation structure is most probably associated with different crystallographic orientation of the initial grains. The fraction of twinned grains increases with the increase of rolling strain (Fig. 2b). The initial grains stretch in the rolling direction, and deformation twins tend to rotate toward the rolling direction (Fig. 2c) at a strain of $60 \%$. The development of shear bands (some of them are highlighted with red dashed lines in Fig. 2c) also has to be noted. As the result, typically heavily-deformed elongated microstructure, composed of pancaked initial grains with twin/subgrain boundaries inside, crossed by shear bands is formed after rolling to $80 \%$ reduction (Fig. 2 d).

Additional information on microstructure evolution during cold rolling was obtained using TEM analysis (Fig. 3). At the early stages of deformation, numerous, mostly individual dislocations are observed (Fig. 3a). With an increase of rolling strain, dislocations start to arrange into dense dislocation pile-ups along the slip planes (Fig. 3b). At further plastic straining to 25\% thickness strain, deformation twins appear (Fig. 3c). The thickness of individual twins is about $20-50 \mathrm{~nm}$, and they tend to be inclined at $45^{\circ}$ to rolling direction. With further increase of rolling strain, more twins are observed; twins cluster into bundles with a thickness of around several hundred $\mathrm{nm}$ (Fig. 3d). Note that the dislocation density also increases pronouncedly. At thickness strains of $60 \%$ and $80 \%$ typical heavily cold rolled lamellar structure, composed of twin boundaries nearly parallel to the rolling direction and developed substructure is observed (Fig. 3e, f). The average transversal spacing between boundaries is $\approx 50 \mathrm{~nm}$ after $80 \%$ thickness strains.

The numerical information on microstructure evolution of the CoCrFeNiMn-1(at.\%)C alloy during cold rolling, including dislocation density and fraction of grains containing twins, is shown in Fig. 4. For the comparison, similar information on the carbon-free CoCrFeNiMn alloy [22] (is) are also presented. Note that dislocation density in the CoCrFeNiMn-1(at.\%)C alloy was measured using XRD analysis and therefore accounts both for the density of intracrystalline dislocation density (dislocations) and for the density of dislocations stored in (sub)grain boundaries. Meanwhile in the CoCrFeNiMn alloy the dislocation density was measured by TEM within grains and subgrains only [22]. The XRD method in the former case was used because the dislocation density was too high to distinguish individual dislocations in TEM images of the CoCrFeNiMn-1(at.\%)C alloy. The results demonstrate that the addition of carbon increases dislocation activity in the alloy (Fig. 4a). At high strains ( $\geq 40 \%$ ), the dislocation density in the carbon-containing alloy is $\sim 2 \times 10^{15} \mathrm{~m}^{-2}$ that is approximately twice higher than that of the base CoCrFeNiMn alloy; however, note that the direct comparison between the values obtained by the different methods is impossible. Carbon also effects on the kinetics of dislocation density increase. In the alloy with carbon, fast increase of dislocation is observed at strains of $\leq 40 \%$, and at higher strains a stage with much slower rate of increase of dislocation density is found. In the carbon-free alloy, the decrease in kinetics is reached already after $25 \%$ rolling strain. On the other hand, the

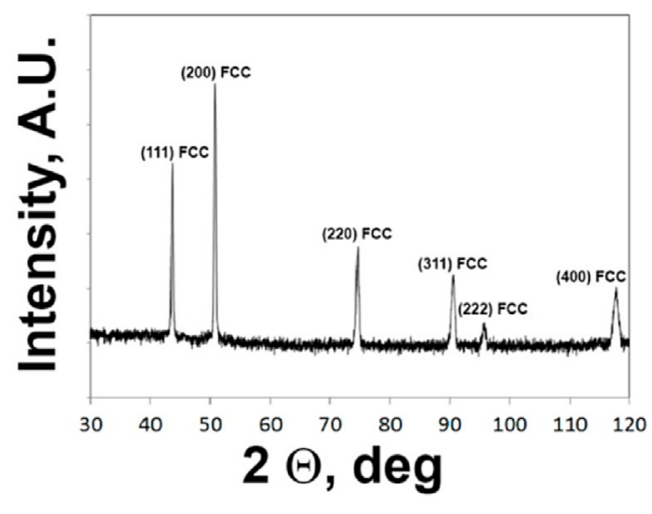

a

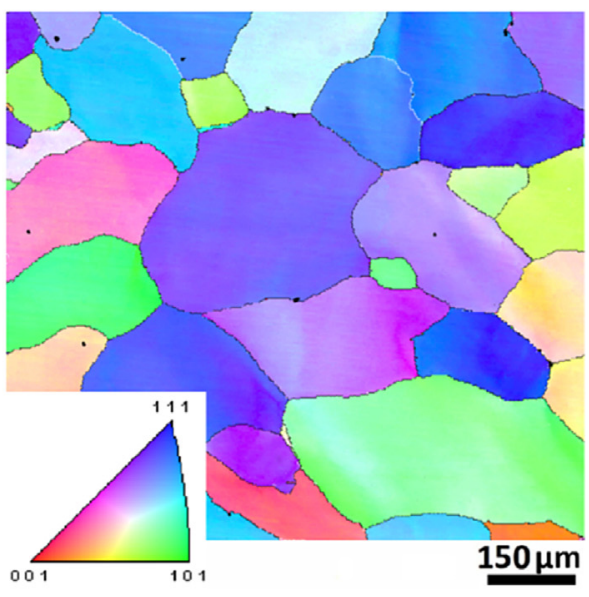

b

Fig. 1. Structure of the CoCrFeNiMn-1(at.\%)C alloy in initial homogenized condition: $a$ - XRD pattern; $b$ - EBSD IPF map. 


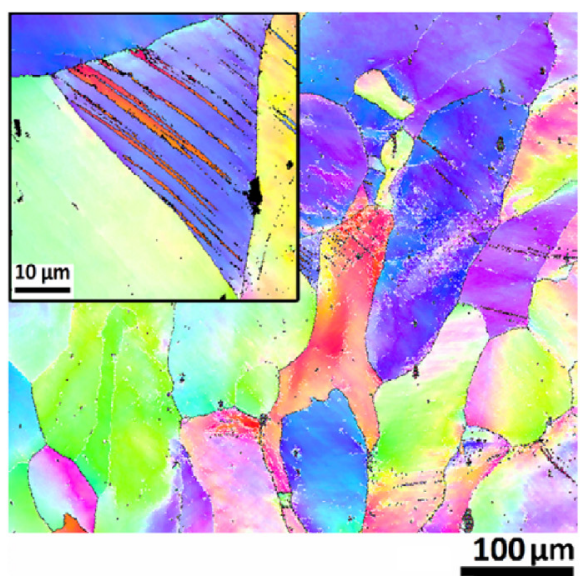

a

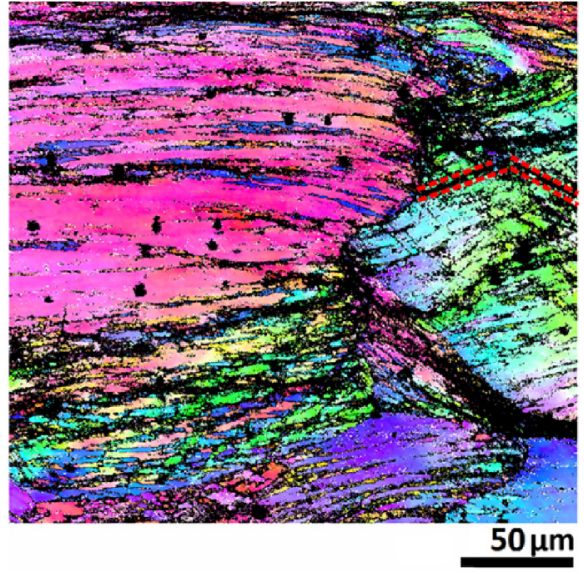

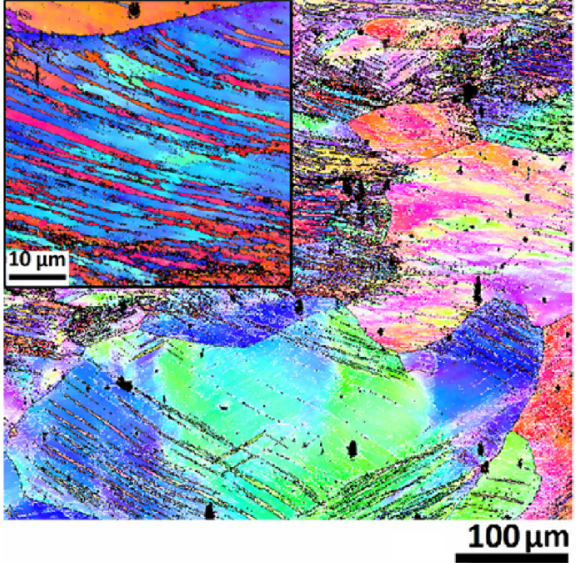

b

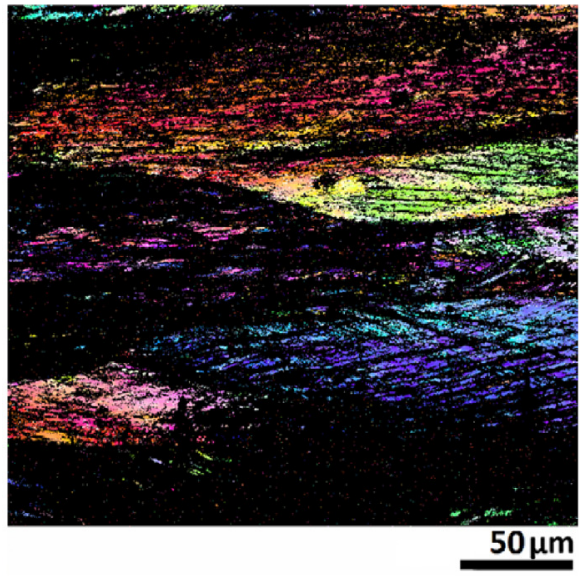

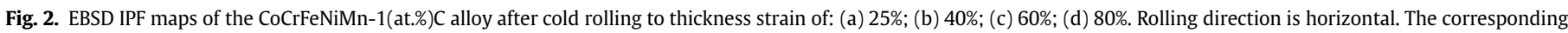
color-coded inverse pole figure is given in Fig. 1b. (For interpretation of the references to colour in this figure legend, the reader is referred to the web version of this article.)

kinetics of twinning becomes slower due to carbon addition (Fig. 4b). For example, in the CoCrFeNiMn-1(at.\%)C alloy no twins are found after $5 \%$ rolling, and fraction of twinned grains equals to 1 (i.e. each grain contains at least one twin) only after 60\% rolling.

\subsection{Effect of annealing on microstructure of the cold-rolled CoCrFeNiMn-1(at.\%)C alloy}

EBSD IPF maps show the microstructure of the CoCrFeNiMn1(at.\%)C alloy after cold rolling to $80 \%$ thickness strain and subsequent annealing at $600-1100^{\circ} \mathrm{C}$ for $1 \mathrm{~h}$ (Fig. 5). Annealing at $600^{\circ} \mathrm{C}$ (Fig. 5a) reduces dislocation density and stresses in the alloy which is mirrored in a lower fraction of un-indexed black points in comparison with the cold-rolled condition (Fig. 2d). However, the morphology of the microstructure seems to be mostly inherited from the deformed condition and only several new recrystallized grains can be found (some of them highlighted with yellow circles in Fig. 5a). Thus recovery mostly takes place during annealing at $600{ }^{\circ} \mathrm{C}$. Complete recrystallization of the cold-rolled material occurs after annealing at $700{ }^{\circ} \mathrm{C}$ (Fig. 5b). The recrystallized structure is very inhomogeneous: alongside with relatively coarse recrystallized grains with order-of-magnitude size of tens of $\mu \mathrm{m}$ (upper part of Fig. 5b), much finer grains with order-of-magnitude size of several $\mu \mathrm{m}$ can be found (lower part of Fig. 5b). The inhomogeneity of the recrystallized microstructure can be caused by the inhomogeneity of the cold-rolled structure (Fig. 2d). The presence of annealing twins, mostly in relatively coarse grains, has to be noted. But even the coarse grains have an irregular shape with many curved boundaries. The microstructure of the CoCrFeNiMn1(at.\%)C alloy becomes more homogeneous after annealing at $800{ }^{\circ} \mathrm{C}$ (Fig. 5c) - there are less fine-grained regions, and most structure is composed of relatively coarse grains. The shape of the grains also becomes closer to regular polygonal one. Further increase of annealing temperature from $900{ }^{\circ} \mathrm{C}$ to $1100{ }^{\circ} \mathrm{C}$ results in an increased recrystallized grain size, more homogeneous structure and an increased fraction of twin boundaries (Fig. 5c-e).

Quantitative analysis of the CoCrFeNiMn-1(at.\%)C alloy microstructure after cold rolling and subsequent annealing at $700-1100{ }^{\circ} \mathrm{C}$, in terms of the mean grain size and the fraction of twin boundaries are shown in Fig. 6a and Fig. 6b, respectively. For the sake of comparison, the corresponding data on the CoCrFeNiMn alloy after similar processing available in Refs. [18,27,29] is also presented. Note that the data on the CoCrFeNiMn-1(at.\%)C alloy annealed at $600{ }^{\circ} \mathrm{C}$ is not presented as the number of recrystallized grains in this condition was not sufficient to measure their size and the fraction of annealing twins reliably. The grain size of the CoCrFeNiMn-1(at.\%)C alloy becomes larger with an increase of annealing temperature (Fig. 6a) from $1.4 \mu \mathrm{m}$ to $69.7 \mu \mathrm{m}$ after annealing at 700 and $1100{ }^{\circ} \mathrm{C}$, respectively. The rate of the microstructure coarsening increases with temperature following the 


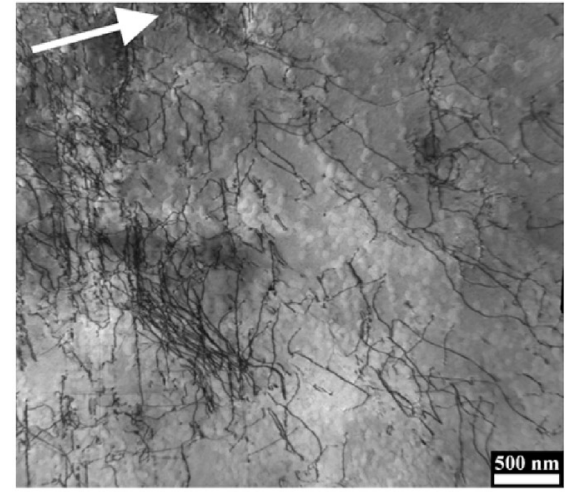

a

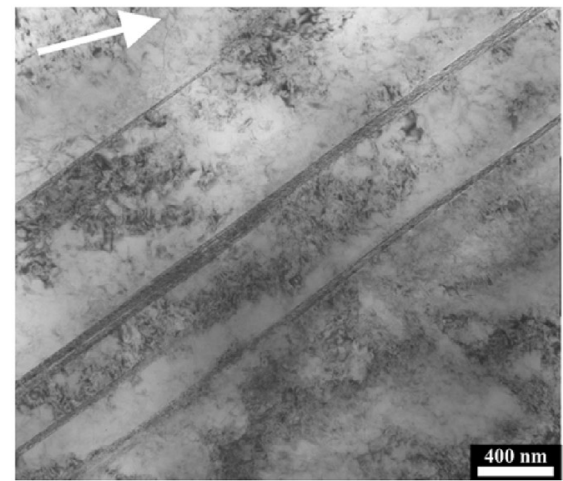

C

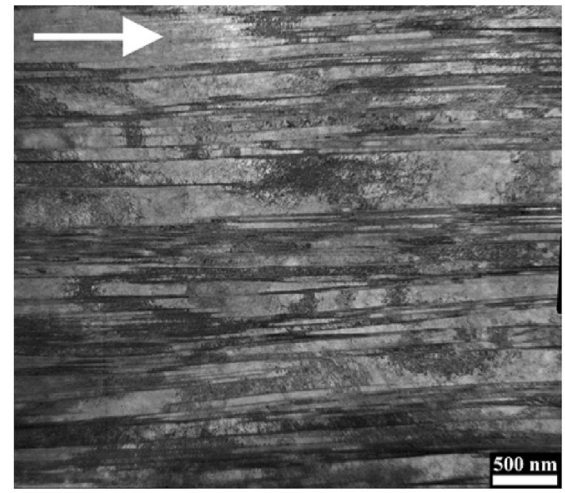

e

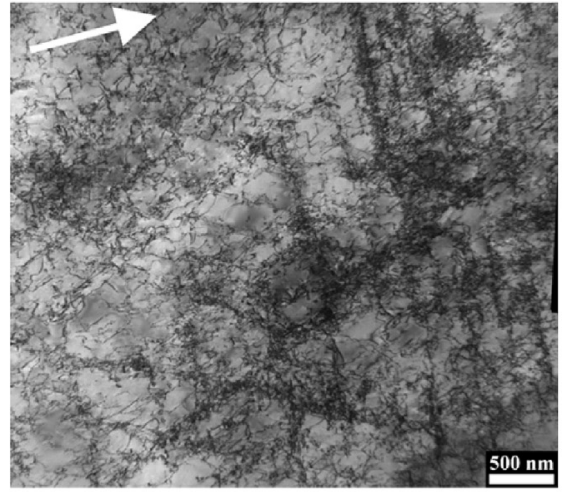

b

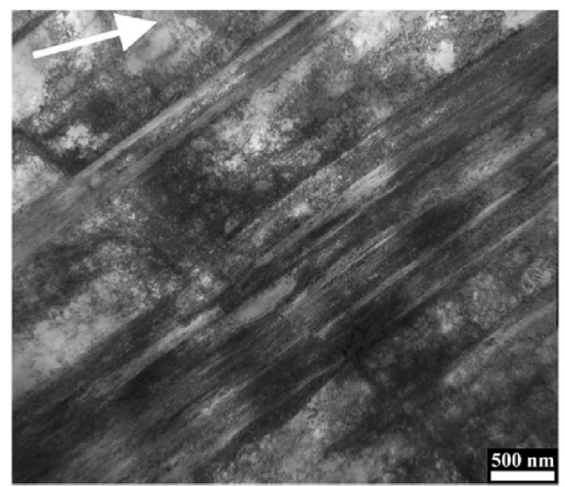

d

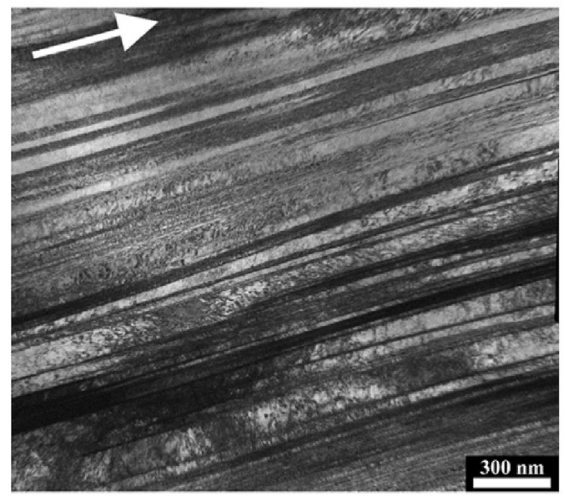

f

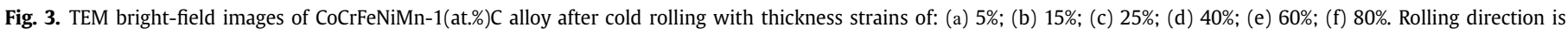
identified with an arrow.

early found relations for the carbon-free CoCrFeNiMn alloy after similar processing [18,27,29] (Fig. 6a). This result does not suggest any noticeable influence of carbon upon grain growth; however, the effect of carbon becomes apparent in the fraction of annealing twin boundaries observed in the recrystallized structure (Fig. 6b). The dependence of twin boundaries fraction on annealing temperature is pronouncedly non-monotonic: an increase from $\sim 0.26$ at $700{ }^{\circ} \mathrm{C}$ to $\sim 0.4$ at $800^{\circ}$, a steady state in the interval $800-1000^{\circ} \mathrm{C}$ and then the fraction of twins again increases to $\sim 0.50$ after annealing at $1100^{\circ} \mathrm{C}$. Much lower fraction of twin boundaries in the alloy annealed at $700{ }^{\circ} \mathrm{C}$ can be attributed to the presence of fine-grained regions in microstructure (Fig. 5a) where the grains mostly do not contain annealing twins. Comparison with the data on carbon-free CoCrFeNiMn alloy demonstrates that the fraction of twins is significantly lower in carbon-free alloy: the fraction of twins in CoCrFeNiMn alloy after annealing at $800-1000{ }^{\circ} \mathrm{C}$ is 0.53-0.57 [27].

In addition to the EBSD investigation, the microstructure of the selected (800 and $1000{ }^{\circ} \mathrm{C}$ ) annealed specimens of the CoCrFeNiMn-1(at.\%)C alloy was examined by TEM to check if second phases (carbides) can form due to annealing. Careful inspection has not revealed any second phases in the sample annealed at $1000{ }^{\circ} \mathrm{C}$, but in the $800{ }^{\circ} \mathrm{C}$ annealed specimen some spherical carbides measuring 50-250 nm diameter are found (Fig. 7). The carbides tend to be located inside grains and not on grain boundaries. Selected area diffraction pattern show that the observed carbides were of $\mathrm{M}_{23} \mathrm{C}_{6}$ type, and EDS analysis reveals that the precipitates were mainly composed of $\mathrm{Cr}$. The precipitation of $\mathrm{Cr}$ - 


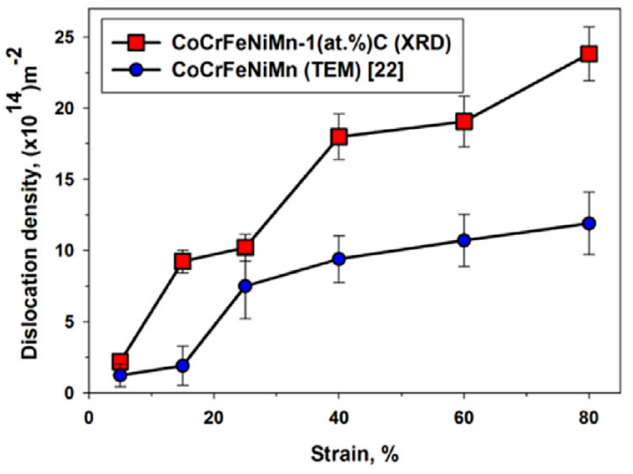

a

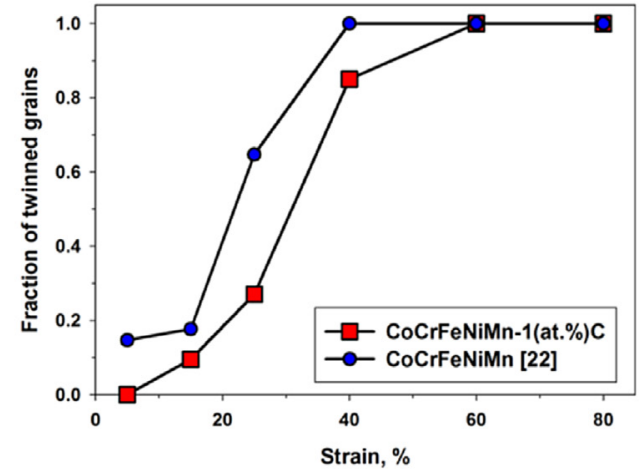

b

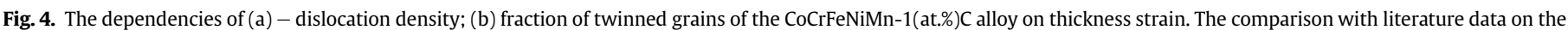
$\mathrm{CoCrFeNiMn}$ alloy is also given. Note the different methods used to measure dislocation density in the alloys.

rich $\mathrm{M}_{23} \mathrm{C}_{6}$ carbides after annealing at $800{ }^{\circ} \mathrm{C}$ agrees with previous data on CoCrFeNiMn-C alloys with higher carbon concentrations [47]. The volume fraction of the observed carbides is very low $(\leq 0.2 \%)$ letting us to consider the alloy in this condition as a single phase alloy.

\subsection{Effect of thermomechanical processing on mechanical properties of the CoCrFeNiMn-1(at.\%)C alloy}

To evaluate the effect of thermomechanical processing on mechanical properties, Vickers microhardness of the CoCrFeNiMn1(at.\%)C alloy was measured at different stages of rolling (Fig. 8a) and after annealing of the $80 \%$ cold-rolled specimens at temperatures of $600-1100{ }^{\circ} \mathrm{C}$ (Fig. 8b). The microhardness values of the CoCrFeNiMn alloy after similar processing [21,22] are also shown. Obviously, rolling results in a pronounced increase of hardness of the CoCrFeNiMn-1(at.\%)C alloy (Fig. 8a): the microhardness increases from $173 \mathrm{HV}$ in the initial homogenized condition to $389 \mathrm{HV}$ after $80 \%$ cold rolling. Note that at the initial stages of deformation (up to $25 \%$ thickness strain) the hardness rapidly increases with an increase in strain and a linear strain/microhardness ratio is maintained. Further rolling of the alloy results in gradual decrease of hardening rate and almost steady state stage is observed at rolling strains of $60-80 \%$. The comparison with the carbon-free $\mathrm{CoCrFe}$ NiMn alloy [22] demonstrates that the hardening behavior of both alloys is rather similar; slightly higher microhardness of the CoCrFeNiMn-1(at.\%)C alloy does usually not exceed the experimental error.

The dependence of microhardness of the CoCrFeNiMn-1(at.\%)C alloy on the annealing temperature (Fig. 8b) is non-monotonic. Annealing at $600{ }^{\circ} \mathrm{C}$ does almost not change the microhardness in comparison with the initial 80\% cold-rolled condition (390 and $395 \mathrm{HV}$, respectively). At higher annealing temperatures a pronounced decrease of hardness is observed. The microhardness decreases to $219 \mathrm{HV}$ after annealing at $700{ }^{\circ} \mathrm{C}$ and to $135 \mathrm{HV}$ at $1100{ }^{\circ} \mathrm{C}$, i.e. softening diminishes with an increase of annealing temperature. The comparison with the data on the CoCrFeNiMn alloy [21] shows that the annealing behavior of both alloys is very similar.

To get a better understanding of the mechanical behavior of the CoCrFeNiMn-1(at.\%)C alloy in different conditions, tensile tests of some selected conditions were performed. Fig. 9 demonstrates stress-strain curves, obtained during tensile testing of the CoCrFeNiMn-1(at.\%)C alloy in the $80 \%$ cold-rolled condition and after annealing at $700{ }^{\circ} \mathrm{C}, 800{ }^{\circ} \mathrm{C}, 900{ }^{\circ} \mathrm{C}$ and $1100{ }^{\circ} \mathrm{C}$. The resulting mechanical properties, namely yield strength $\left(\sigma_{0.2}\right)$, ultimate tensile strength ( $\sigma_{\mathrm{UTS}}$ ), elongation to fracture $(\delta)$ and uniform elongation $\left(\delta_{\mathrm{u}}\right)$ are summarized in Table 1 . The cold-rolled condition of the alloy demonstrates high yield strength of $1360 \mathrm{MPa}$, but a negligible strain hardening capacity results in poor ductility - the uniform elongation is only $0.5 \%$, and the total elongation is $15 \%$. Nevertheless, the ultimate tensile strength of the cold-rolled alloy is as high as $1470 \mathrm{MPa}$. Annealing increases the strain hardening capacity and the ductility of the alloy. For example, after annealing at $700{ }^{\circ} \mathrm{C}$ the alloy shows the uniform elongation of $6 \%$, but at the expense of reduced strength - the yield strength of the alloy is $1070 \mathrm{MPa}$, and the ultimate tensile strength is $1270 \mathrm{MPa}$. An increase of annealing temperature results in further softening of the alloy. After annealing at $1100{ }^{\circ} \mathrm{C}$, the alloy has high ductility - the uniform elongation is $46 \%$ and the elongation to fracture is $66 \%$, but the strength is relatively low - the yield strength is $380 \mathrm{MPa}$ and the ultimate tensile strength is $810 \mathrm{MPa}$. Observation of fracture surfaces (not shown) has revealed typical dimpled ductile fracture in all specimens. The size of the dimples becomes larger with increase of annealing temperature.

\section{Discussion}

\subsection{Effect of carbon on microstructure evolution in the CoCrFeNiMn-1(at.\%)C alloy during thermomechanical processing}

Although significant attention is paid to the development of new compositions of high entropy alloys, the effect of alloying is generally studied by revealing changes in phase composition and microstructure of the alloys in as-cast or heat-treated conditions and their mechanical properties [2]. The potential alloying effect on deformation mechanisms, including mechanisms governing the microstructure evolution during thermomechanical processing, have received much less attention $[39,45,50]$. But the present results demonstrate that alloying even with the relatively small amount of carbon can result in pronounced changes in the microstructural evolution of the fcc CoCrFeNiMn alloy during cold rolling. The sequence of deformation mechanisms operating in the CoCrFeNiMn alloy during cold rolling was proposed in Ref. [22]. It includes dislocation activity at the earlier stages of deformation, further deformation twinning, and formation of shear bands at latter stages of deformation. The same mechanisms were found to operate in the CoCrFeNiMn-1(at.\%)C alloy, however, their activity at different stages of deformation is significantly different from the undoped alloy. The most obvious difference is much slower twinning kinetics (Fig. 4b), and higher dislocation activity (Fig. 4a). It should be noted that these observations are in 


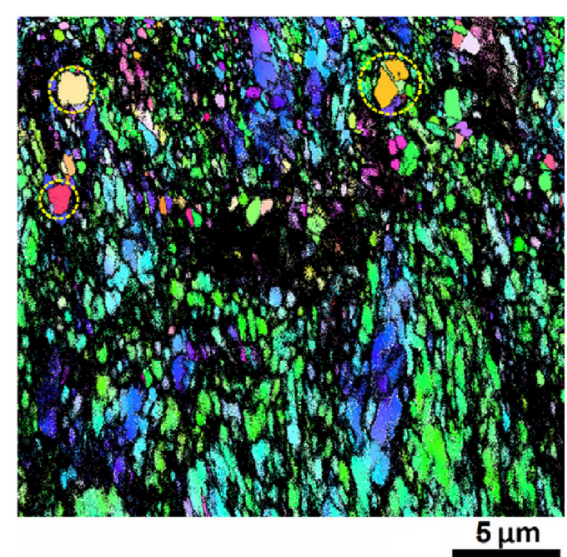

a

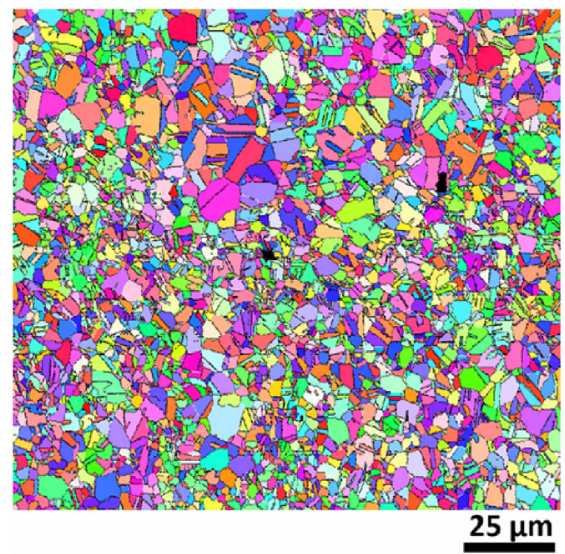

$\mathrm{c}$

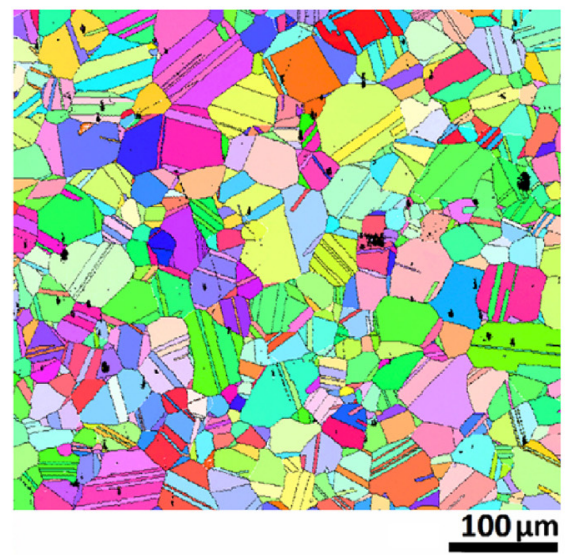

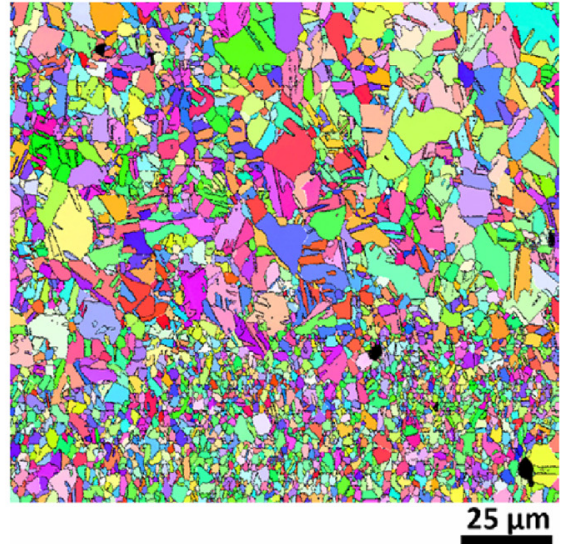

b

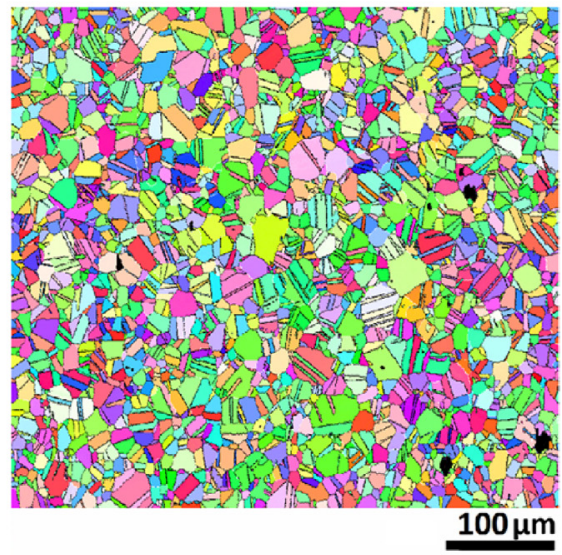

d

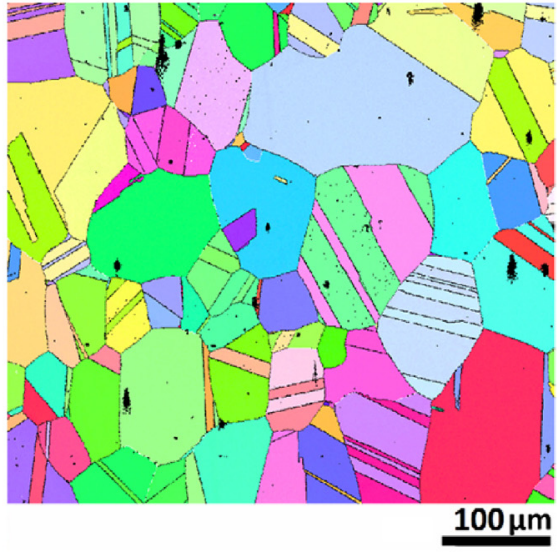

f

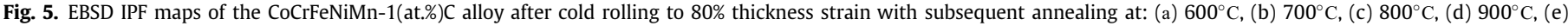

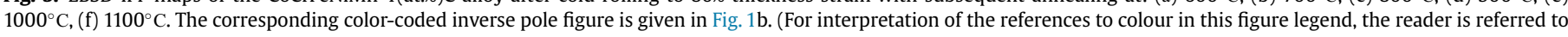
the web version of this article.)

contrast to the reported effect of 0.5 at.\% of $C$ on the mechanical behavior of the CoCrFeNiMn alloy, which resulted in more active mechanical twinning at room temperature [45].

Generally, the active deformation mechanisms at selected temperature are believed to be dependent on stacking fault energy (SFE) in materials exhibiting deformation-induced twinning or deformation-induced phase transformations [23]. Although there is no solid consensus, the TWIP effect in austenitic steels is expected when the SFE is in the range of $20-40 \mathrm{~mJ} / \mathrm{m}^{2}$ [51]. The reported room temperature SFE values for the CoCrFeNiMn alloy $\left(18.3-27.3 \mathrm{~mJ} / \mathrm{m}^{2}\right)$ approximately fell in this range $[52,53]$. It was established that carbon pronouncedly increases SFE of TWIP steels [54] and Fe-Cr-Ni-based stainless steels [55]. Taking into account similarity of composition and mechanical behavior of the $\mathrm{CoCrFe}-$ NiMn alloy and austenitic steels $[21,22]$ it seems reasonable that the SFE of the CoCrFeNiMn-1(at.\%)C alloy is higher than that of the 


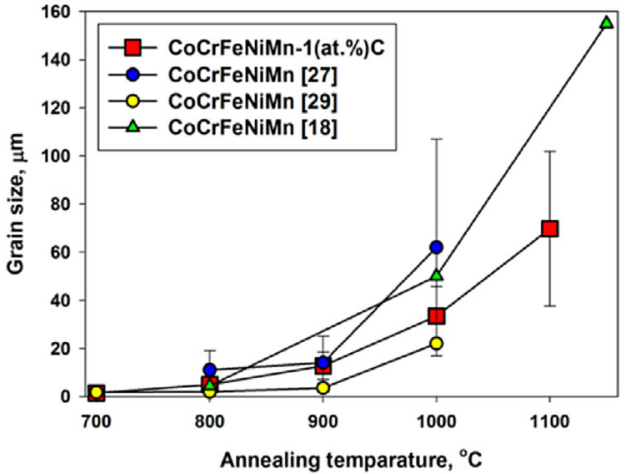

a

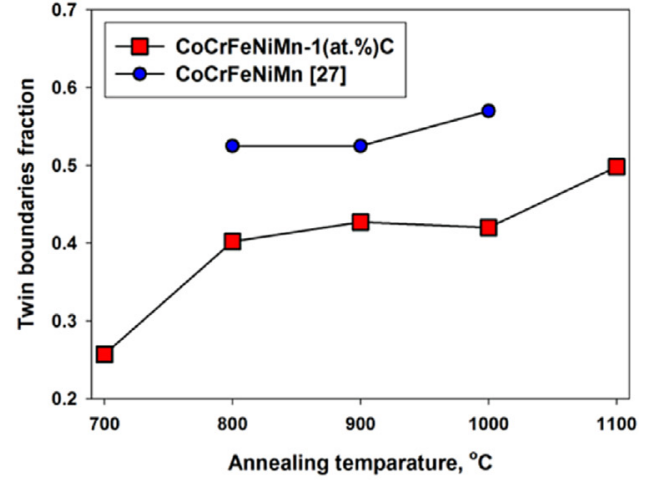

b

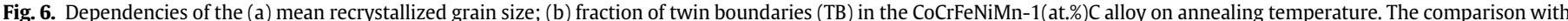

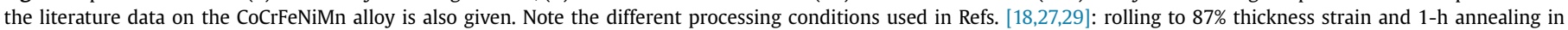
Ref. [18], rolling to 84\% thickness strain and 1-h annealing in Ref. [27] and rolling to 90\% thickness strain and 1-h annealing in Ref. [29].

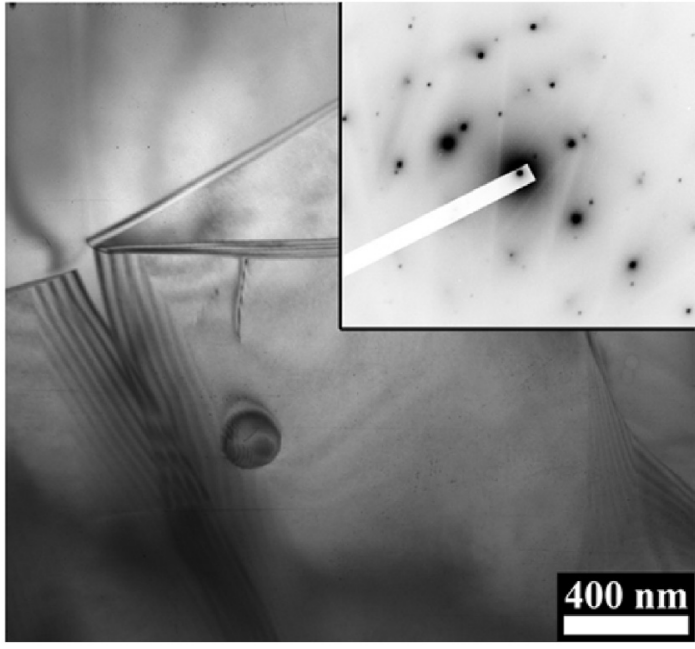

Fig. 7. TEM bright-field image of the CoCrFeNiMn-1(at.\%)C alloy after cold rolling to $80 \%$ thickness strain and subsequent annealing at $800^{\circ} \mathrm{C}$; the corresponding selected area electron diffraction pattern is inserted.

CoCrFeNiMn alloy. If this is the case, at early stages of deformation dislocation slip may be preferred to mechanical twinning due to

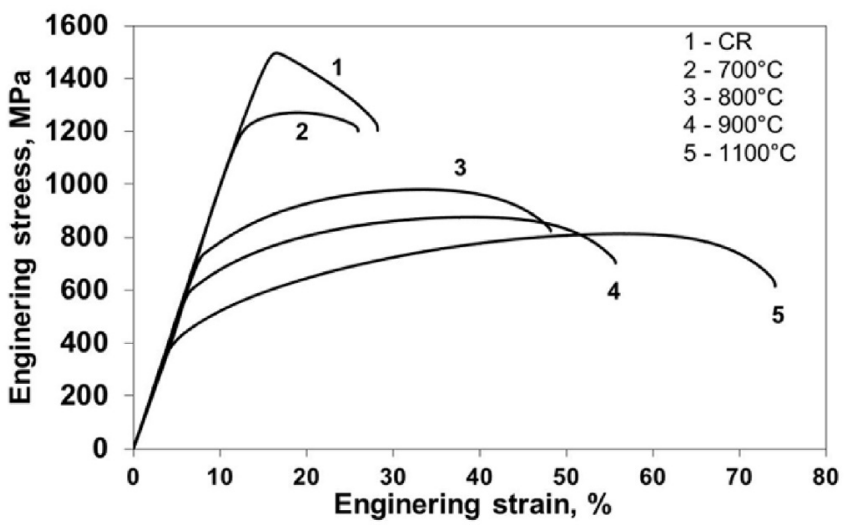

Fig. 9. Engineering stress-strain curves obtained during tensile testing of the CoCrFeNiMn-1(at.\%)C alloy after cold rolling to $80 \%$ thickness strain and subsequent annealing at $700{ }^{\circ} \mathrm{C}, 800{ }^{\circ} \mathrm{C}, 900{ }^{\circ} \mathrm{C}$ and $1100{ }^{\circ} \mathrm{C}$.

lower stresses required for dislocation slip in the carbon-containing alloy as the width of dissociated dislocations is lower in higher SFE materials [56]. Presumably, the increased dislocation density at higher strains (Fig. 4a) will increase stresses required for dislocation slip due to the mutual interaction between lattice dislocations thereby activating mechanical twinning. This scenario agrees well

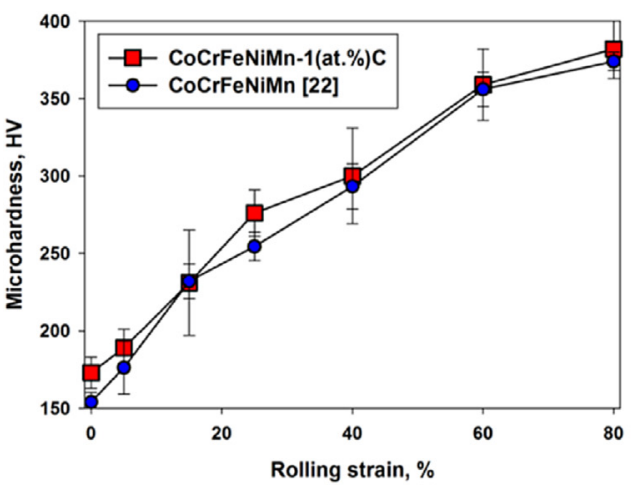

a

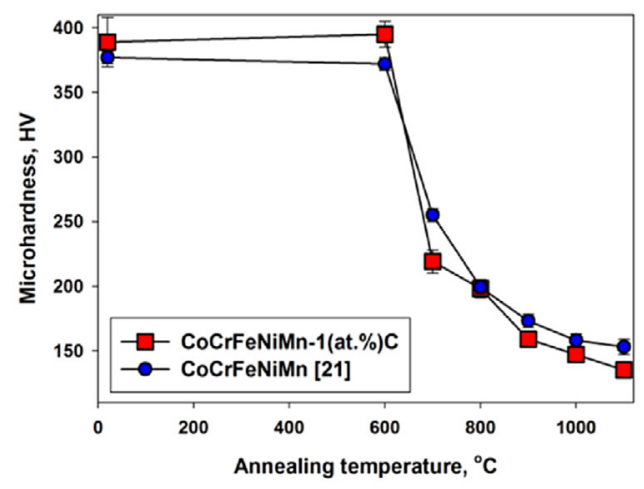

b

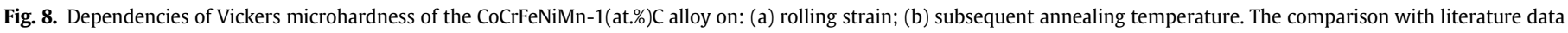
on the CoCrFeNiMn alloy is also given. Note the different annealing conditions used in Ref. [21]: the annealing time was $1 \mathrm{~h}$. 
Table 1

Tensile mechanical properties of the CoCrFeNiMn-1(at.\%)C alloy after cold rolling to $80 \%$ thickness strain and subsequent annealing at $700^{\circ} \mathrm{C}, 800^{\circ} \mathrm{C}, 900^{\circ} \mathrm{C}$ and $1100^{\circ} \mathrm{C}$.

\begin{tabular}{lllll}
\hline Annealing temperature, ${ }^{\circ} \mathrm{C}$ & $\sigma_{0.2}$ & $\sigma_{\mathrm{UTS}}$ & $\delta, \%$ & $\delta_{\mathrm{u}}, \%$ \\
\hline Cold-rolled & 1360 & 1470 & 15 & 0.5 \\
700 & 1070 & 1270 & 14 & 6 \\
800 & 720 & 980 & 37 & 21 \\
900 & 570 & 880 & 48 & 30 \\
1100 & 380 & 810 & 66 & 46 \\
\hline
\end{tabular}

with the microstructural observations. The similar changes in deformation mechanisms were observed in the $\mathrm{Fe}-20 \mathrm{Mn}-\mathrm{xCu}-1.3 \mathrm{C}(\mathrm{x}=0,1.5$ and 3.0) TWIP steels and were attributed to increase of SFE with an increase of copper content [57]. Despite such a pronounced changes in the activity of deformation mechanisms at different stages of strain, hardening during cold rolling occurs very similarly in both CoCrFeNiMn and CoCrFeNiMn-1(at.\%)C alloys (Fig. 8a). It suggests that the total contribution of different strengthening mechanisms (dynamic Hall-Petch effect due to twinning, an increase in dislocation density and development of substructure) give approximately the same value.

The increased SFE in the CoCrFeNiMn-1(at.\%)C alloy can also be confirmed by a lower fraction of annealing twins after annealing in comparison with that in the CoCrFeNiMn alloy [26] (Fig. 6b). It is established that the fraction of annealing twins is inversely proportional to SFE of the alloy [58]. Note that the fraction of annealing twins is the only difference in recrystallization behavior between the CoCrFeNiMn and CoCrFeNiMn-1(at.\%)C alloy, as the morphology of microstructure (Fig. 5), recrystallized grain size (Fig. 6a) and softening behavior (Fig. 8b) of both alloys are almost identical.

\subsection{Microstructure-properties relationship in the CoCrFeNiMn- 1(at.\%)C alloy}

The mechanical properties of the CoCrFeNiMn-1(at.\%)C alloy show apparent dependencies on thermomechanical treatment conditions and resulting microstructure: cold rolling results in pronounced hardening of the alloy due to increased dislocation density and mechanical twinning (Fig. 8a) and 80\% cold rolled alloy demonstrates impressive tensile strength (Fig. 9 and Table 1 ) but at the expense of very poor uniform elongation. Comparison with tensile properties of the similarly processed CoCrFeNiMn alloy [22] shows that the carbon-containing alloy has higher strength (ultimate tensile strength of $1470 \mathrm{MPa} v s .1175 \mathrm{MPa}$ ) and comparable ductility (elongation to fracture of $15 \%$ vs. $14.4 \%$ ). One should note that the CoCrFeNiMn-1(at.\%)C alloy has almost identical strength to that of the cryo-rolled CoCrFeNiMn alloy (1495 MPa) [22]. Higher strength of the carbon-containing CoCrFeNiMn-1(at.\%)C alloy can be attributed to (i) the solid-solution strengthening effect of carbon [46,47]; and (ii) the higher dislocation density (Fig. 4a).

Annealing at $700-1100{ }^{\circ} \mathrm{C}$ causes softening (Fig. 8b) and increases ductility of the cold-rolled CoCrFeNiMn-1(at.\%)C alloy. In terms of microstructure, softening is highly anticipated as recrystallization takes place at these temperatures. However, even in the recrystallized condition the CoCrFeNiMn-1(at.\%)C alloy demonstrates relatively high strength. For example, after $800{ }^{\circ} \mathrm{C}$ annealing, the alloy has a mean grain size of $4.9 \mu \mathrm{m}$, yield strength of $720 \mathrm{MPa}$, ultimate tensile strength of $980 \mathrm{MPa}$ and elongation to fracture of $37 \%$. These values are unexpectedly high for the nearly single fcc phase alloy with the recrystallized microstructure. To compare, the CoCrFeNiMn alloy with grain size of $4.4 \mu \mathrm{m}$ has yield strength of $\approx 355 \mathrm{MPa}$, ultimate tensile strength of $\approx 660 \mathrm{MPa}$ and elongation to fracture of $\approx 36 \%$ [18], i.e. the carbon-containing alloy with almost the same grain size has twice higher yield strength, 50\% higher ultimate tensile strength and the same ductility as carbon-free alloy. Even the coarse-grained CoCrFeNiMn-1(at.\%)C alloy produced by cold rolling and subsequent annealing at $1100{ }^{\circ} \mathrm{C}$ with a grain size of $69.7 \mu \mathrm{m}$ has much higher strength than the CoCrFeNiMn alloy with the grain size of $50 \mu \mathrm{m}$ : the respective values of yield strength are $380 \mathrm{MPa}$ and $\approx 190 \mathrm{MPa}$ [18]. Therefore, the reasons for the superior strength of the recrystallized carbon-containing CoCrFeNiMn-1(at.\%)C alloy are worth to be explored.

Several strengthening mechanisms can operate in recrystallized CoCrFeNiMn-1(at.\%)C alloy, namely, grain boundary (Hall-Petch) strengthening, solid solution strengthening and precipitation strengthening. Although some individual precipitates were found in the $800^{\circ} \mathrm{C}$ annealed alloy (Fig. 7), their small volume fraction and large spacing between the precipitates presumably make their contribution to the strength of the alloy negligible. The yield strength of the CoCrFeNiMn-1(at.\%)C alloy pronouncedly decreases with the increase of annealing temperature from 700 to $1100{ }^{\circ} \mathrm{C}$ (Table 1), and in the same temperature range the recrystallized grain size significantly increases (Fig. 6a). This might imply that strong Hall-Petch strengthening occurs in the CoCrFeNiMn-1(at.\%)C

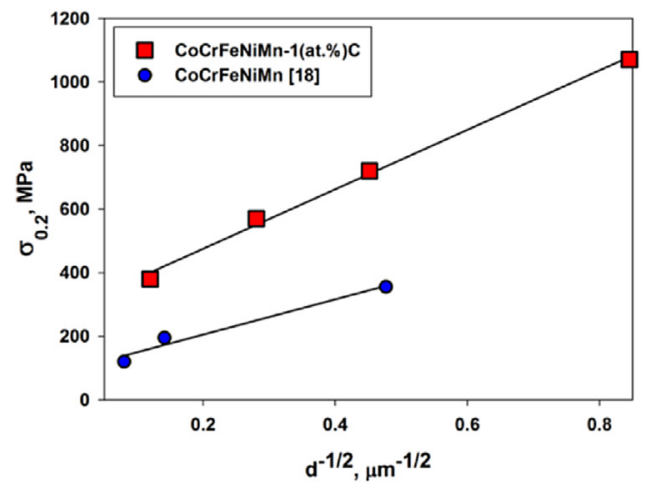

a

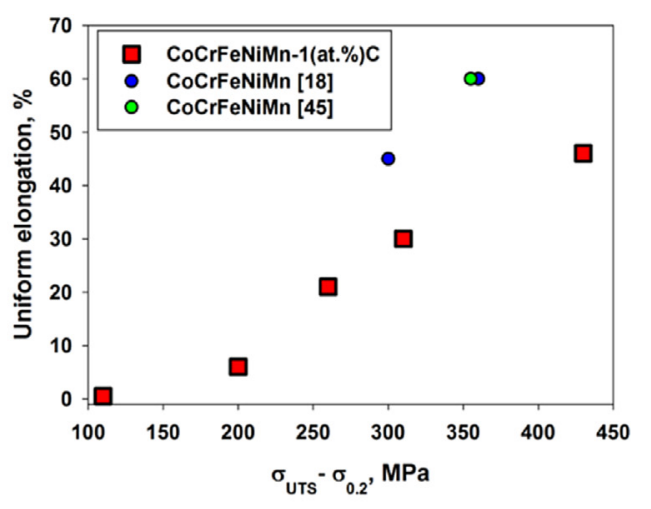

$\mathrm{b}$

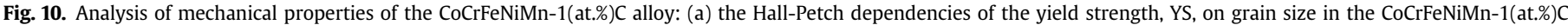

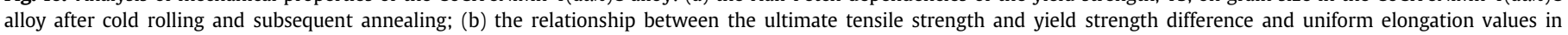
different conditions. The comparison with literature data on the CoCrFeNiMn alloy is also given. 
alloy. To estimate the grain boundary strengthening, Hall-Petch dependence between yield strength of the CoCrFeNiMn-1(at.\%)C alloy in different conditions and the grain size has been plotted in Fig. 10a.

The produced Hall-Petch plot (Fig. 10a) demonstrates that strong dependence between the grain size and the yield strength exists in the annealed CoCrFeNiMn-1(at.\%)C alloy. The dependence is governed by the following equation:

$\sigma_{0.2}=288.15+935.25 \mathrm{~d}^{-1 / 2}$

where $\sigma_{0.2}$ is the yield strength (in MPa), $d$ is the grain size (in $\mu \mathrm{m}$ ) $\sigma_{0}=288.15(\mathrm{MPa})$ is the friction stress, and $k=935.25\left(\mathrm{MPa} \times \mu \mathrm{m}^{-1}\right)$

2 ) is the Hall-Petch coefficient. The slope of the Hall-Petch curve of the studied CoCrFeNiMn-1(at.\%)C alloy is noticeably higher than that of the carbon-free CoCrFeNiMn alloy: the Hall-Petch coefficient of the "pure" CoCrFeNiMn alloy is only $538 \mathrm{MPa} \times \mu \mathrm{m}^{-1 / 2}$ [18]. The Hall-Petch coefficient of the CoCrFeNiMn alloy was reported to be unexpectedly high for the fcc alloy [24], and present results suggest that it increases very pronouncedly due to carbon addition. The increase of Hall-Petch coefficient is the indication that slip transfer between different grains becomes harder. The apparent explanation can be preferred segregation of carbon atoms on grain boundaries. However, the EDS scanning has not revealed enrichment of grain boundaries with carbon. Another indirect confirmation that carbon does not segregate on grain boundaries can be found in the distribution of carbides in the CoCrFeNiMn-1(at.\%)C alloy after $800{ }^{\circ} \mathrm{C}$ annealing (Fig. 9). The carbides are found inside grains and not on the grain boundaries. Presumable, at the annealing temperature of $800^{\circ} \mathrm{C}$ the pipe diffusion of carbon in the fcc phase of the CoCrFeNiMn-1(at.\%)C alloy can be fast enough to promote precipitation of carbides on lattice dislocations during the very initial stages of annealing process. This observation contradicts the idea of preferred segregation of carbon on grain boundaries. Therefore, present results do not confirm the suggestion that increase of Hall-Petch coefficient in the carbon-containing CoCrFeNiMn-1(at.\%)C alloy in comparison with the carbon-free $\mathrm{CoCrFeNiMn}$ alloy is due to carbon segregations on grain boundaries. Additional investigations of the reasons for the increased Hall-Petch coefficient are thus required.

In addition to the higher $k$ coefficient in the CoCrFeNiMn-1(at.\%) $\mathrm{C}$, the friction stress $\left(\sigma_{0}\right)$ value of $288.15 \mathrm{MPa}$ is also higher than that reported for the CoCrFeNiMn alloy $-125 \mathrm{MPa}$ [18]. The increase of friction stress can possibly be attributed to solid solution strengthening effect caused by carbon. Indeed, the CoCrFeNiMn1(at.\%)C alloy contains $\approx 1$ at.\% (or $\approx 0.2 \mathrm{wt} \%$ ) of carbon in solid solution. Linear dependence between the carbon concentration and the yield strength has been established for different austenitic steels and it was found that the yield strength increases by 76.6 MPa per 1 at.\% of carbon in stainless steels [59] and by $42 \mathrm{MPa}$ / at\% C in TWIP steels [60]. However, the difference between the friction stresses of the CoCrFeNiMn-1(at.\%)C and CoCrFeNiMn alloys is much higher - $\approx 160 \mathrm{MPa}$. Probably, complex stress fields around each atom in the fcc lattice of the CoCrFeNiMn-based alloys due to the differences in atomic sizes and shear modulus of the composing elements may increase the strengthening effect of carbon in comparison with more dilute steels. The developed theoretical approaches for solid solution strengthening in HEAs account only for substitutional solid solutions $[38,61,62]$ and therefore it difficult to make any calculation to prove this assumption. However, the previously reported data on CoCrFeNiMn-0.5 (at.\%) $\mathrm{C}$ and $\mathrm{Fe}_{40 \cdot 4} \mathrm{Ni}_{11 \cdot 3} \mathrm{Mn}_{34 \cdot 8} \mathrm{Al}_{7 \cdot 5} \mathrm{Cr}_{6}-1.1$ (at.\%) $\mathrm{C}$ alloys $[45,46]$ confirm strong solid solution strengthening effect of $\mathrm{C}$. In the CoCrFeNiMn-0.5 (at.\%) $\mathrm{C}$ alloy, the yield strength increases by $\approx 120 \mathrm{MPa} / \mathrm{at} \% \mathrm{C}$, while in the $\mathrm{Fe}_{40 \cdot 4} \mathrm{Ni}_{11 \cdot 3} \mathrm{Mn}_{34 \cdot 8} \mathrm{Al}_{7 \cdot 5} \mathrm{Cr}_{6}-1.1$ (at.\%) $\mathrm{C}$ the increase of yield strength is $178 \mathrm{MPa} / \mathrm{at} \% \mathrm{C}$. These values are reasonably close to the increase of friction stress of the CoCrFeNiMn alloy due to alloying with 1 at.\% of carbon found in current study - $\approx 160 \mathrm{MPa} /$ at $\% \mathrm{C}$, taking into account the experimental uncertainties. Thus the increase in friction stress in equation (3) in the carbon-containing CoCrFeNiMn-1(at.\%)C alloy in comparison with "pure" CoCrFeNiMn can be attributed to solid solution strengthening.

It is also worth to estimate the effect of carbon on ductility of the CoCrFeNiMn-based alloys. The CoCrFeNiMn alloy demonstrates an impressive tensile ductility at room temperature due to a high strength hardening capacity [18]. The difference between the ultimate tensile strength ( $\left.\sigma_{\text {UTS }}\right)$ and the yield strength $\left(\sigma_{0.2}\right)$ can be used as a measure of the strain hardening capacity [45]. Therefore, we have plotted the relationship between the $\sigma_{\text {UTS }}-\sigma_{0.2}$ values and the uniform elongation $\left(\delta_{\mathrm{u}}\right)$ values (Table 1 ) for the CoCrFeNiMn1(at.\%)C alloy in different conditions (Fig. 10b). Literature information on the carbon-free CoCrFeNiMn alloy $[18,45]$ is also provided. One can see that the ductility increases with the increase of the strain hardening capacity both in the CoCrFeNiMn-1(at.\%)C and CoCrFeNiMn alloys. However, less expected fact is that the dots corresponding to the carbon-free CoCrFeNiMn alloy are found above the CoCrFeNiMn-1(at.\%)C alloy dots, i.e. at the given $\sigma_{U T S}-$ $\sigma_{0.2}$ value the uniform elongation will be lower in the alloy doped with carbon. This should be the reason why the ductility of the CoCrFeNiMn-1(at.\%)C alloy even with coarse recrystallized grains is lower than that of the CoCrFeNiMn alloy [18]. Alloying with carbon changes relative contributions of dislocation activity and mechanical twinning at different stages of plastic deformation (previous section) and therefore possibly affects the tensile strain hardening behavior of the alloy thereby decreasing its ductility. Additional work is required to prove this suggestion, however.

To sum up, the present study demonstrates that the CoCrFeNiMn-1(at.\%)C alloy after cold rolling and recrystallization annealing has very attractive mechanical properties. For example, the CoCrFeNiMn-1(at.\%)C alloy with fine recrystallized microstructure demonstrates the tensile strength of nearly $1 \mathrm{GPa}$ with ductility of $37 \%$ (Table 1), which is competitive to the best precipitation-hardened HEAs [8]. In the field of new HEAs development, little attention is paid to the usage of interstitial elements, but many commercial alloys heavily rely on the presence of interstitial elements. Current results together with other recent reports $[45,46]$ show that the interstitial alloying of HEAs may be promising for obtaining alloys with enhanced properties. By proper thermomechanical processing, the strength-ductility combination of the alloys can be tailored to meet specific requirements. However, additional experimental and theoretical investigations are needed to establish the effects of interstitial elements on phase formation, deformation and strengthening mechanisms and other important aspects.

\section{Conclusions}

In presents study the effect of cold sheet rolling to $80 \%$ thickness strain and subsequent annealing at $600-1100{ }^{\circ} \mathrm{C}$ for $1 \mathrm{~h}$ on microstructure and mechanical properties of the CoCrFeNiMn high entropy alloy containing 1 at.\% of carbon (CoCrFeNiMn-1(at.\%)C alloy) were studied. The following conclusions can be drawn from this work:

1) After homogenization annealing at $1000{ }^{\circ} \mathrm{C}$ for $24 \mathrm{~h}$ the CoCrFeNiMn-1(at.\%)C alloy has a single fcc solid solution phase structure. The microstructure of the alloy is composed of coarse equiaxed grains with a size of $250-300 \mu \mathrm{m}$.

2) The microstructure evolution during cold rolling of the CoCrFeNiMn-1(at.\%)C alloy is associated with dislocation slip at 
early stages of deformation, and deformation twinning and shear band formation during further deformation. As the result, a fine lamellar structure with transversal spacing between boundaries of $\approx 50 \mathrm{~nm}$ and high dislocation density of $\sim 2 \times 10^{15} \mathrm{~m}^{-2}$ is formed after thickness strain of $80 \%$. Comparison with the CoCrFeNiMn alloy demonstrates that dislocation density is higher in the carbon-doped alloy, while twinning kinetics is slower. The changes in the contribution of different deformation mechanisms were attributed to increase of SFE due to carbon doping.

3) Annealing of the $80 \%$ cold rolled CoCrFeNiMn-1(at.\%)C alloy at $600{ }^{\circ} \mathrm{C}$ results mostly in recovery and only few recrystallized grains appear. Annealing at $700-1100^{\circ}$ results in complete recrystallization of the alloy. The average size of recrystallized grains increases with the increase of annealing temperature from $1.4 \mu \mathrm{m}$ after annealing at $700{ }^{\circ} \mathrm{C}$ to $69.7 \mu \mathrm{m}$ after annealing at $1100{ }^{\circ} \mathrm{C}$.

4) Rolling results in continuous increase of microhardness of the CoCrFeNiMn-1(at.\%)C alloy from 173 HV in the initial homogenized condition to $389 \mathrm{HV}$ after $80 \%$ cold rolling. After $80 \%$ rolling, the alloy has yield strength, ultimate tensile strength, and elongation to fracture of $1360 \mathrm{MPa}, 1470 \mathrm{MPa}$ and 15\%, respectively.

5) The CoCrFeNiMn-1(at.\%)C alloy becomes softer and more ductile with increase of annealing temperature from $700{ }^{\circ} \mathrm{C}$ to $1100{ }^{\circ} \mathrm{C}$, for example, yield strength decreases from $1070 \mathrm{MPa}$ to $380 \mathrm{MPa}$, and elongation to fraction increases from 14\% to $66 \%$. After annealing at certain conditions, the alloy demonstrates a balanced combination of mechanical properties. For example, after annealing at $800{ }^{\circ} \mathrm{C}$ alloy has yield strength of $720 \mathrm{MPa}$, ultimate tensile strength of $980 \mathrm{MPa}$, uniform elongation of $21 \%$ and elongation to fracture of $37 \%$. High strength of the CoCrFeNiMn-1(at.\%)C after recrystallization annealing was attributed to strong grain boundary strengthening. Solid solution strengthening by carbon also contributes to the strength of the alloy.

\section{Acknowledgement}

The authors gratefully acknowledge the financial support from the Russian Science Foundation Grant No. 14-19-01104. The authors are grateful to the personnel of the Joint Research Centre, Belgorod State University, for their assistance with the instrumental analysis.

\section{References}

[1] J.-W. Yeh, S.-K. Chen, S.-J. Lin, J.-Y. Gan, T.-S. Chin, T.-T. Shun, C.-H. Tsau, S.Y. Chang, Nanostructured high-entropy alloys with multiple principle elements: novel alloy design concepts and outcomes, Adv. Eng. Mater. 6 (8) (2004) 299-303.

[2] Y. Zhang, T.T. Zuo, Z. Tang, M.C. Gao, K.A. Dahmen, P.K. Liaw, Z.P. Lu, Microstructures and properties of high-entropy alloys, Prog. Mater. Sci. 61 (2014) $1-93$.

[3] O.N. Senkov, G.B. Wilks, J.M. Scott, D.B. Miracle, Mechanical properties of $\mathrm{Nb}_{25} \mathrm{Mo}_{25} \mathrm{Ta}_{25} \mathrm{~W}_{25}$ and $\mathrm{V}_{20} \mathrm{Nb}_{20} \mathrm{Mo}_{20} \mathrm{Ta}_{20} \mathrm{~W}_{20}$ refractory high entropy alloys, Intermetallics 19 (5) (2011) 698-706.

[4] O.N. Senkov, S.V. Senkova, D.B. Miracle, C. Woodward, Mechanical properties of low-density, refractory multi-principal element alloys of the Cr-Nb-Ti-V-Zr system, Mater. Sci. Eng. A 565 (2013) 51-62.

[5] O.N. Senkov, C. Woodward, D.B. Miracle, Microstructure and properties of aluminum-containing refractory high-entropy alloys, JOM 66 (10) (2014) 2030-2042.

[6] N.D. Stepanov, N.Yu. Yurchenko, D.V. Skibin, M.A. Tikhonovsky, G.A. Salishchev, Structure and mechanical properties of the AlCrxNbTiV ( $x=0$, 0.5, 1, 1.5) high entropy alloys, J. Alloys Compd. 652 (2015) 266-280.

[7] N.D. Stepanov, N.Yu. Yurchenko, V.S. Sokolovsky, M.A. Tikhonovsky, G.A. Salishchev, An AlNbTiVZr 0.5 high-entropy alloy combining high specific strength and good ductility, Mater. Lett. 161 (2015) 136-139.

[8] J.Y. He, H. Wang, H.L. Huang, X.D. Xu, M.W. Chen, Y. Wu, X.J. Liu, T.G. Nieh, K. An, Z.P. Lu, A precipitation-hardened high-entropy alloy with outstanding tensile properties, Acta Mater. 102 (2016) 187-196.
[9] H.M. Daoud, A.M. Manzoni, N. Wanderka, U. Glatzel, High-temperature tensile strength of $\mathrm{Al}_{10} \mathrm{CO}_{25} \mathrm{Cr}_{8} \mathrm{Fe}_{15} \mathrm{Ni}_{36} \mathrm{Ti}_{6}$ compositionally complex alloy (High-Entropy alloy), JOM 67 (10) (2015) 2271-2277.

[10] M.H. Chuang, M.H. Tsai, W.R. Wang, S.J. Lin, J.W. Yeh, Microstructure and wear behavior of AlxCo1.5CrFeNi1.5Tiy high-entropy alloys, Acta Mater. 59 (16) (2011) 6308-6317.

[11] B. Cantor, I.T.H. Chang, P. Knight, A.J.B. Vincent, Microstructural development in equiatomic multicomponent alloys, Mater. Sci. Eng. A 375-377 (2004) $213-218$.

[12] F. Otto, Y. Yang, H. Bei, E.P. George, Relative effects of enthalpy and entropy on the phase stability of equiatomic high-entropy alloys, Acta Mater. 61 (2013) 2628-2638.

[13] G.A. Salishchev, M.A. Tikhonovsky, D.G. Shaysultanov, A.V. Kuznetsov, I.V. Kolodiy, A.S. Tortika, O.N. Senkov, Effect of Mn and V on structure and mechanical properties of high-entropy alloys based on CoCrFeNi system, J. Alloys Compd. 591 (2014) 11-21.

[14] M. Laurent-Brocq, A. Akhatova, L. Perrière, S. Chebini, X. Sauvage, E. Leroy, Y. Champion, Insights into the phase diagram of the CrMnFeCoNi high entropy alloy, Acta Mater. 88 (2015) 355-365.

[15] B. Schuh, F. Mendez-Martin, B. Völker, E.P. George, H. Clemens, R. Pippan, A. Hohenwarter, Mechanical properties, microstructure and thermal stability of a nanocrystalline CoCrFeMnNi high-entropy alloy after severe plastic deformation, Acta Mater. 96 (2015) 258-268.

[16] E.J. Pickering, E. Munoz-Moreno, H.J. Stone, H.G. Jones, Precipitation in the equiatomic high-entropy alloy CrMnFeCoNi, Scr. Mater. 113 (2015) 106-109.

[17] N.D. Stepanov, D.G. Shaysultanov, M.S. Ozerov, S.V. Zherebtsov, G.A. Salishchev, Second phase formation in the CoCrFeNiMn high entropy alloy after recrystallization annealing, Mater. Lett. 185 (2016) 1-4.

[18] F. Otto, A. Dlouhy, C. Somsen, H. Bei, G. Eggeler, E.P. George, The influences of temperature and microstructure on the tensile properties of a CoCrFeMnNi high-entropy alloy, Acta Mater. 61 (2013) 5743-5755.

[19] A. Gali, E.P. George, Tensile properties of high-and medium-entropy alloys, Intermetallics 39 (2013) 74-78.

[20] B. Gludovatz, A. Hohenwarter, D. Catoor, E.H. Chang, E.P. George, R.O. Ritchie A fracture-resistant high-entropy alloy for cryogenic applications, Science 345 (2014) 1153-1158.

[21] A.J. Zaddach, A.J. Scattergood, A.J. Koch, Tensile properties of low-stacking fault energy high-entropy alloys, Mater. Sci. Eng. A 636 (2015) 373-378.

[22] N. Stepanov, M. Tikhonovsky, N. Yurchenko, D. Zyabkin, M. Klimova, S. Zherebtsov, A. Efimov, G. Salishchev, Effect of cryo-deformation on structure and properties of CoCrFeNiMn high-entropy alloy, Intermetallics 59 (2015) 8-17.

[23] O. Bouaziz, S. Allain, C.P. Scott, P. Cugy, D. Barbier, High manganese austenitic twinning induced plasticity steels: a review of the microstructure properties relationships, Curr. Opin. Solid State Mater. Sci. 15 (4) (2011) 141-168.

[24] W.H. Liu, Y. Wu, J.Y. He, T.G. Nieh, Z.P. Lu, Grain growth and the Hall-Petch relationship in a high-entropy FeCrNiCoMn alloy, Scr. Mater. 68 (7) (2013) 526-529.

[25] N.D. Stepanov, D.G. Shaysultanov, N.Y. Yurchenko, S.V. Zherebtsov, A.N. Ladygin, G.A. Salishchev, M.A. Tikhonovsky, High temperature deformation behavior and dynamic recrystallization in CoCrFeNiMn high entropy alloy, Mater. Sci. Eng. A 636 (2015) 188-195.

[26] G. Laplanche, O. Horst, F. Otto, G. Eggeler, E.P. George, Microstructural evolution of a CoCrFeMnNi high-entropy alloy after swaging and annealing, J. Alloys Compd. 647 (2015) 548-557.

[27] F. Otto, N.L. Hanold, E.P. George, Microstructural evolution after thermomechanical processing in an equiatomic, single-phase CoCrFeMnNi highentropy alloy with special focus on twin boundaries, Intermetallics 54 (2014) 39-48.

[28] Z. Wu, H. Bei, F. Otto, G.M. Pharr, G.M. George, Recovery, recrystallization, grain growth and phase stability of a family of FCC-structured multicomponent equiatomic solid solution alloy, Intermetallics 46 (2014) 131-140.

[29] P.P. Bhattacharjee, G.D. Sathiaraj, M. Zaid, J.R. Gatti, C. Lee, C.W. Tsai, J.W. Yeh, Microstructure and texture evolution during annealing of equiatomic $\mathrm{CoCr}$ FeMnNi high-entropy alloys, J. Alloys Compd. 587 (2014) 544-552.

[30] P.P. Bhattacharjee, G.D. Sathiaraj, C.W. Tsai, J.W. Yeh, Effect of heavy cryorolling on the evolution of microstructure and texture during annealing of equiatomic CoCrFeMnNi high entropy alloy, Intermetallics 69 (2016) 1-9.

[31] B.R. Chen, A.C. Yeh, J.W. Yeh, Effect of one-step recrystallization on the grain boundary evolution of CoCrFeMnNi high entropy alloy and its subsystems, Sci. Rep. 6 (2016) 22306.

[32] D.H. Lee, I.C. Choi, M.Y. Seok, J. He, Z. Lu, J.Y. Suh, M. Kawasaki, T.G. Langdon, J.I. Jang, Nanomechanical behavior and structural stability of a nanocrystalline CoCrFeNiMn high-entropy alloy processed by high-pressure torsion, J. Mater. Res. 30 (18) (2015) 2804-2815.

[33] Z. Wu, H. Bei, G.M. Pharr, E.P. George, Temperature dependence of the mechanical properties of equiatomic solid solution alloys with face-centered cubic crystal structures, Acta Mater. 81 (2014) 428-441.

[34] B. Gludovatz, A. Hohenwarter, K.V. Thurston, H. Bei, Z. Wu, E.P. George R.O. Ritchie, Exceptional damage-tolerance of a medium-entropy alloy CrCoNi at cryogenic temperatures, Nat. Commun. 7 (2016) 10602.

[35] M.J. Yao, K.G. Pradeep, C.C. Tasan, D. Raabe, A novel, single phase, nonequiatomic FeMnNiCoCr high-entropy alloy with exceptional phase stability and tensile ductility, Scr. Mater. 72 (2014) 5-8.

[36] Y. Deng, C.C. Tasan, K.G. Pradeep, H. Springer, A. Kostka, D. Raabe, Design of a 
twinning-induced plasticity high entropy alloy, Acta Mater. 94 (2015) 124-133.

[37] K.G. Pradeep, C.C. Tasan, M.J. Yao, Y. Deng, H. Springer, D. Raabe, Nonequiatomic high entropy alloys: approach towards rapid alloy screening and property-oriented design, Mater. Sci. Eng. A 648 (2015) 183-192.

[38] N.D. Stepanov, D.G. Shaysultanov, M.A. Tikhonovsky, G.A. Salishchev, Tensile properties of the $\mathrm{Cr}-\mathrm{Fe}-\mathrm{Ni}-\mathrm{Mn}$ non-equiatomic multicomponent alloys with different Cr contents, Mater. Des. 87 (2015) 60-65.

[39] Z. Li, K.G. Pradeep, Y. Deng, D. Raabe, C.C. Tasan, Metastable high-entropy dual-phase alloys overcome the strength-ductility trade-off, Nature 534 (2016) 227-230.

[40] W.-R. Wang, W.-L. Wang, S.-C. Wang, Y.-C. Tsai, C.-H. Lai, J.-W. Yeh, Effects of $\mathrm{Al}$ addition on the microstructure and mechanical property of AlxCoCrFeNi high-entropy alloys, Intermetallics 26 (2012) 44-51.

[41] J.Y. He, W.H. Liu, H. Wang, Y. Wu, X.J. Liu, T.G. Nieh, Z.P. Lu, Effects of Al addition on structural evolution and tensile properties of the FeCoNiCrMn high-entropy alloy system, Acta Mater. 62 (2014) 105-113.

[42] T.-T. Shun, Y.-C. Du, Age hardening of the $\mathrm{Al}_{0.3} \mathrm{CoCrFeNiC}_{0.1}$ high entropy alloy, J. Alloys Compd. 478 (2009) 269-272.

[43] Y.P. Wang, D.Y. Li, L. Parent, H. Tian, Improving the wear resistance of white cast iron using a new concept-High-entropy microstructure, Wear 271 (9) (2011) 1623-1628.

[44] S. Fang, W. Chen, Z. Fu, Microstructure and mechanical properties of twinned $\mathrm{Al}_{0.5} \mathrm{CrFeNiCO}_{0.3} \mathrm{C}_{0.2}$ high entropy alloy processed by mechanical alloying and spark plasma sintering, Mater. Des. 54 (2014) 973-979.

[45] Z. Wu, C.M. Parich, H. Bei, Nano-twin mediated plasticity in carbon-containing FeNiCoCrMn high entropy alloys, J. Alloys Compd. 647 (2015) 815-822.

[46] Z. Wang, I. Baker, Interstitial Strengthening of a f.c.c. FeNiMnAlCr High entropy alloy, Mater. Lett. 180 (2016) 153-156.

[47] N.D. Stepanov, N.Yu Yurchenko, M.A. Tikhonovsky, G.A. Salishchev, Effect of carbon content and annealing on structure and hardness of the CoCrFeNiMnbased high entropy alloys, J. Alloys Compd. 687 (2016) 59-71.

[48] R.E. Smallman, K.H. Westmacott, Stacking faults in face-centred cubic metals and alloys, Philos. Mag. 2 (1957) 669-683.

[49] G.K. Williamson, W.H. Hall, X-ray line broadening from filed aluminium and wolfram, Acta Metall. 1 (1953) 22-31.

[50] A. Tazzudin, K. Biswas, N.P. Gurao, Deciphering micro-mechanisms of plastic deformation in a novel single phase fcc-based MnFeCoNiCu high entropy alloy using crystallographic texture, Mater. Sci. Eng. A 657 (2016) 224-233.

[51] P.S. Kusakin, R.O. Kaibyshev, High-Mn twinning-induced plasticity steels: microstructure and mechanical properties, Rev. Adv. Mater. Sci. 44 (2016) $326-360$.

[52] A.J. Zaddach, C. Niu, C.C. Koch, L. Irwing, Mechanical properties and stacking fault energies of NiFeCrCoMn high-entropy alloy, JOM 65 (12) (2013) 1780-1789.

[53] S. Huang, W. Li, S. Lu, F. Tian, J. Shen, E. Holmstrom, L. Vitos, Temperature dependent stacking fault energy of FeCrCoNiMn high entropy alloy, Scr. Mater. 108 (2015) 44-47.

[54] A. Saeed-Akbari, J. Imlau, U. Prahl, W. Bleck, Derivation and variation in composition-dependent stacking fault energy maps based on subregular solution model in high-manganese steels, Metall. Mater. Trans. A 40 (13) (2009) 3076-3090.

[55] R.E. Schramm, P.P. Reed, Stacking fault energies of seven commercial austenitic stainless steels, Metall. Trans. A 6A (1975) 1345-1351.

[56] G. Gottstein, Physical Foundations of Materials Science, Springer-Verlag Berlin Heidelberg, Berlin, 2004

[57] X. Peng, D. Zhu, Z. Hu, W. Yi, H. Liu, M. Wang, Stacking fault energy and tensile deformation behavior of high-carbon twinning-induced plasticity steels: effect of Cu addition, Mater. Des. 45 (2013) 518-523.

[58] X.H. An, S.D. Wu, Z.F. Zhang, R.B. Figueiredo, N. Gao, T.G. Langdon, Enhanced strength-ductility synergy in nanostructured $\mathrm{Cu}$ and $\mathrm{Cu}-\mathrm{Al}$ alloys processed by high-pressure torsion and subsequent annealing, Scr. Mater. 66 (5) (2012) $227-230$.

[59] V.G. Gavrilyuk, H. Berns, High Nitrogen Steels: Structure, Properties, Manufacture, Applications, Springer-Verlag, Berlin, 1999.

[60] O. Bouaziz, H. Zurob, B. Chehab, J.D. Embury, S. Allain, M. Huang, Effect of chemical composition on work hardening of Fe-Mn-C TWIP steels, Mater. Sci. Tech. 27 (3) (2011) 707-709.

[61] I. Toda-Caraballo, P.E. Rivera-Díaz-del-Castillo, Modelling solid solution hardening in high entropy alloys, Acta Mater. 85 (2015) 14-23.

[62] R.S. Mishra, N. Kumar, M. Komarasamy, Lattice strain framework for plastic deformation in complex concentrated alloys including high entropy alloys, Mater. Sci. Tech. 31 (10) (2015) 1259-1263. 